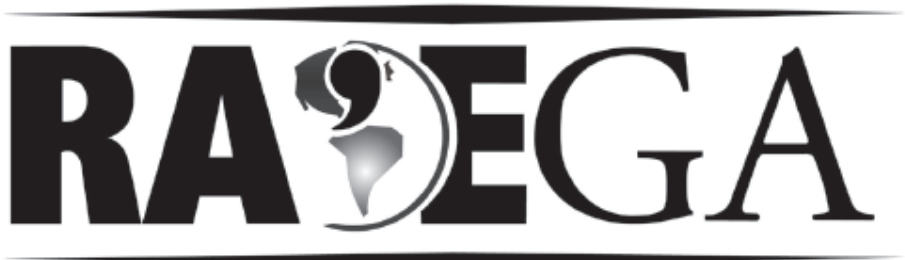

O ESPAÇO GEOGRÁFICO EM ANÁLISE

\title{
IDENTIDADE DE LUGAR: UM ESTUDO SOBRE UM GRUPO DE MORADORES ATINGIDOS POR BARRAGENS NO MUNICÍPIO DE TIMBÉ DO SUL, SANTA CATARINA
}

\section{THE IDENTITY OF A PLACE: A STUDY OF A GROUP OF RESIDENTS AFFECTED BY DAMS IN TIMBÉ DO SUL, SANTA CATARINA}

\author{
Rosevane ARCARO ${ }^{1}$ \\ Teresinha Maria GONÇALVES ${ }^{2}$
}

\section{RESUMO}

Este estudo mostra o processo de ruptura da identidade de lugar de moradores das comunidades de Areia Branca e Rio do Salto, no município de Timbé do Sul (SC), desalojados de suas propriedades para a instalação de uma barragem no Rio do Salto. O estudo se insere no campo da psicologia ambiental e da geografia cultural e tem como objeto de pesquisa a identidade de lugar. A pesquisa caracteriza-se por uma abordagem qualitativa, tendo como principal método a história de vida e como principal técnica a entrevista narrativa. Todos os entrevistados demonstraram temor e insegurança em relação ao futuro, o que nos remete a um novo pensar sobre o processo de desalojamento de populações.

Palavras-chave: Identidade de lugar; Psicologia Ambiental; Espaço-Identidade; Subjetividade-Apego.

\footnotetext{
${ }^{1}$ Licenciada em geografia pela Universidade do Extremo Sul Catarinense, de Criciúma, Santa Catarina, Brasil. Mestre em Ciências Ambientais pela Universidade do Extremo Sul Catarinense de Criciúma, Santa Catarina, Brasil. rosiarcarao@hotmail.com

2 Bacharel em Serviço Social pela Pontifícia Universidade Católica do Paraná,Brasil. Mestre em Psicologia Social Pela Pontifícia Universidade Católica de São Paulo, Brasil. Doutora em Meio Ambiente e Desenvolvimento pela Universidade Federal do Paraná, Brasil. teresaakira@gmail.com
} 


\section{ABSTRACT}

This study shows the rupture process of place identity of the residents and communities of Areia Branca and Rio do Salto in Timbé do Sul-SC, who were displaced from their properties for the installation of a dam across the Rio do Salto. The study belongs to the field of Environmental Psychology and Cultural Geography and it focuses on the Identity of place. The research is characterized by a qualitative approach and the method comprises life history and narrative interviewing. All respondents showed fear and insecurity towards the future, which leads us to new thinking about the process of displacement of populations.

Keywords: place identity; Environmental Psychology; space-identity; subjectivity-attachment.

\section{INTRODUÇÃO}

A história vivenciada pelos moradores das comunidades de Areia Branca e Rio do Salto não é muito diferente da história de outras pessoas que foram atingidas pelo processo de construção de barragens e privadas de morar no espaço que organizaram conforme seu gosto.

Em ambas as comunidades citadas, há mais de 20 anos, está em andamento um empreendimento que levará o nome de Barragem Rio do Salto. Desde os primeiros estudos sobre a construção da mesma, os moradores atingidos não obtiveram informações sobre o desenrolar do empreendimento, fazendo com que seu desânimo e incerteza aumentassem.

Atualmente, nas comunidades, observam-se 0 desinteresse e 0 inconformismo dos moradores, pois convivem, no seu local de origem, com crateras causadas pela retirada de argila, casas velhas e mal-arrumadas. Aquele lugar conhecido como lugar de sossego tornou-se um lugar de conflitos sociais. A barragem atingirá 129 propriedades, das quais 51 foram desapropriadas, restando somente 78 , onde residem 85 famílias, totalizando 300 moradores.

O empreendimento visa resolver problemas de abastecimento de água potável, irrigação de cultivos, nesse caso, a rizicultura, contenção de cheias, entre outros. Os municípios favorecidos pelo empreendimento são Timbé do 
Sul, Turvo, Ermo, Morro Grande, Meleiro e Araranguá, que compõem a bacia hidrográfica do rio Araranguá.

A instalação da barragem Rio do Salto, além dos problemas humanos e sociais irá, necessariamente, reconfigurar o território.

\begin{abstract}
A instalação de barragens provoca uma verdadeira reordenação territorial, exigindo a remoção compulsória das populações, causando não somente a perda de identidade coletiva decorrente da perda da propriedade rural e dos padrões de organização social, como relações de parentesco, amizade e comunidade, construída pelos moradores, assim como a história de vida pessoal de cada um, sendo intransferível e impossível de ser refeita da mesma forma em outro lugar (REIS, 2007, p.474).
\end{abstract}

O lugar tem um significado para o indivíduo que o incorpora à própria identidade. Na construção da identidade, existem dimensões e características do entorno físico, que são incorporadas pelo sujeito por meio da interação com o ambiente. Nesse sentido, a identidade de lugar é um componente específico do próprio "eu" do sujeito, forjado em um complexo de ideias conscientes e inconscientes, sentimentos, valores, objetivos, preferências, habilidades e tendências (GONÇALVES, 2007).

A formação da identidade de lugar é decorrente da apropriação do espaço. Essa, por sua vez, é compreendida como o sentimento de possuir e gestionar um espaço por uso habitual ou por identificação, com o conceito de espaço, abarcando os espaços físicos, sociais, psíquicos e culturais. "Um sujeito, ao apropriar-se de um lugar, com o tempo, deixa sua marca e, ao transformá-lo, inicia um processo de reapropriação com o ambiente, colocando nele objetos com o qual se identifica" (GONÇALVES, 2007, p.28-29).

Cada sujeito se apropria de um lugar de forma diferenciada, dependendo, portanto, de modelos culturais, sociais, estilo de vida, entre outros. "Os processos de apropriação são complexos e se dividem em dois aspectos fundamentais: comportamentais de ação-transformação e de identidade de lugar simbólica - identidade do sujeito com o espaço, na qual se incluem os processos afetivos, cognitivos e interativos" (GONÇALVES, 2007, p.29). 
Através do conceito de identidade, os moradores de Areia Branca e Rio do Salto relatam sua história de vida, seus lugares íntimos, a afetividade que têm com o lugar, mostrando que, quando um sujeito se identifica com o lugar e se apropria dele, faz de tudo para vê-lo organizado, colocando nele objetos com o qual o identifica.

\section{BARRAGEM RIO DO SALTO}

As comunidades de Areia Branca e Rio do Salto localizam-se no interior do município de Timbé do Sul, em Santa Catarina. Juntas contam com uma população de 320 habitantes.

A economia predominante nas comunidades está voltada ao plantio de fumo, banana, milho, cana-de-açúcar, arroz, eucalipto e pastagens. Há em pequenos números nas propriedades a existência de pomares junto às moradias.

$\mathrm{Na}$ comunidade de Areia Branca, há extração de uma argila especial destinada ao fabrico de pisos cerâmicos, abastecendo as empresas que atuam no local desde 2007, como Vectra, Itagrês e De Luca.

\footnotetext{
A falta de tratamento de esgotos domésticos e industriais, resíduos de mineração e o uso excessivo de agrotóxicos na agricultura são responsáveis pela contaminação das águas dos afluentes do rio Araranguá, provocando escassez de água potável, em especial nos municípios de Turvo e Meleiro, dessa forma tem-se cogitado, portanto, a construção de uma barragem na área rural do Rio do Salto, localizado no município de Timbé do Sul (SC) (RIMA, 2007, p.29).
}

Os municípios impactados socioeconomicamente pelo empreendimento proposto (Timbé do Sul, Turvo, Ermo, Morro Grande, Meleiro e Araranguá) pertencem à área da bacia hidrográfica do rio Araranguá.

A realização da obra visa atender interesses econômicos dos municípios de Turvo, Meleiro, Araranguá e Ermo, que serão beneficiados pelo empreendimento, pois terão água potável para consumo humano, atividades ligadas à agricultura e à indústria. 
De acordo com o Estudo do Relatório de Impacto Ambiental Rima Epagri (2000) e o Estudo de Impacto Ambiental e Relatório de Impacto Ambiental EIA/Rima - Epagri (2006), os municípios do Vale do Araranguá produzem grande quantidade de arroz. Os agricultores do vale possuem terras próximas à várzea dos rios Amola Faca, Figueira, Manoel Alves, Jundiá, Turvo e Itoupava. Em épocas de plantio, verificam-se atritos entre rizicultores e a Casan pelo uso da água. Segundo os rizicultores da região, a construção de uma barragem poderia diminuir esses conflitos.

Levantamentos realizados por técnicos da empresa Magna, citados no EIA/Rima - Epagri (2006), identificam na área a ser alagada pelo empreendimento, 129 propriedades das quais 51 já foram desapropriadas e, em 78 propriedades, residem 85 famílias que totalizam 300 moradores.

Até o presente momento, foram indenizadas 31 propriedades. Segundo o secretário de Estado do Desenvolvimento Regional de Araranguá, o passo seguinte seria buscar recursos para o pagamento das indenizações às propriedades restantes, para que, no início de 2011, seja dada continuação a esse processo. Acredita-se que o restante das indenizações seja pago em breve, pois se sabe que moradores vêm aguardando a barragem há mais de 20 anos e que esse problema é um dos fatores responsáveis pelo entrave do desenvolvimento da economia local (JORNAL SEM CENSURA, 2010).

$\mathrm{Na}$ área em que será construída a barragem, percebe-se que os moradores deixaram de investir em suas propriedades, hesitam em realizar reformas ou até mesmo pequenos reparos em suas casas. Esse sentimento de abandono se reflete na própria visualização cênica das comunidades, as mesmas tornaram-se áreas abandonadas, casas velhas e mal-arrumadas, crateras para todo lado, montes de argila, restos de construções abandonadas por moradores já desapropriados. Segundo os proprietários das olarias, não adianta investir nas mesmas, pois as propriedades já foram valoradas pela Casan. "Investir seria jogar dinheiro fora".

Desde as primeiras notícias sobre a construção do empreendimento, os moradores das comunidades de Rio do Salto e Areia Branca passaram a experimentar um processo de crescente apreensão, transtornos, brigas, 
tristeza, estresse, sentimento de abandono e desmotivação, que podem ser observados no seguinte relato:

Tudo isso é muito ruim para a comunidade, estamos esperando por uma decisão e ainda não obtivemos. Algumas famílias foram indenizadas, outras ainda não, estão à espera de uma indenização justa para que possam migrar para outra região. Já faz mais de 20 anos que se fala em barragem e ainda não saiu. Essa história de barragem tem sido uma sombra na vida das pessoas. Desde que começou a se falar da barragem, nós vivemos com uma sombra. Não conseguimos empréstimos dos bancos para investirmos em nossas propriedades. O que nos é colocado é que nossa comunidade é uma área de utilidade pública. Perdemos muito com essa barragem.

Um dos entrevistados, ao ser questionado sobre a construção da barragem e as consequências na sua família (mudança) e para a comunidade (desintegração), deu o seguinte depoimento: "Primeiro, nasci aqui e me criei aqui. Segundo, eu não me acostumo com o barulho que tem na cidade. Terceiro, se na agricultura está ruim, na cidade é pior".

Outra moradora entrevistada observou que muitos bens e benfeitorias não possuem apenas valor de mercado, o qual geralmente é fácil de ser quantificado, mas principalmente valor sentimental, que não tem como ser mensurado. Ela dá o seguinte depoimento:

Cada pau, cada pedra aqui tem uma história. Este pomar, o jardim, a minha casa tem um grande valor. Hoje o que me entristece é que estou morando numa casa que não é mais minha. Já recebi a indenização da minha propriedade, o que mais me aborrece é que não fui eu que fiz a valoração das minhas terras. Simplesmente me impuseram um valor e tive que aceitar. Com o dinheiro que recebi não vai dar para comprar em outro lugar as mesmas coisas que tenho aqui. Tudo lá fora é muito caro.

Um dos entrevistados relata a preocupação sobre a necessidade de uma orientação sobre a administração do possível dinheiro a ser recebido a título da indenização. Na sua concepção, muitas pessoas não estão preparadas para receber o dinheiro e correm o risco de ficarem sem nada: "Vê o dinheiro, pensa 
que é muito, daqui a um ano não tem mais nada".

Conforme estudos realizados nas comunidades de Areia Branca e Rio do Salto, mencionados no EIA/Rima - Epagri (2006), os moradores que se autodefinem "contra a barragem" argumentam que o motivo reside na questão humano-cultural, ou seja, ali é o lugar onde nasceram, cresceram, formaram famílias e onde pretendiam permanecer. É comum nas referidas comunidades pais deixarem como herança terras para seus filhos. Esse processo é contínuo, passando de geração a geração.

Para o camponês, a terra é mais que objeto, é meio de produção. A luta dos camponeses não é uma luta por qualquer terra, mas sim uma luta por terra que tem incorporado o seu trabalho. Nesse sentido, não se trata de uma luta pequenoburguesa pela propriedade, mas sim uma luta pelo objetivo e meio de seu trabalho (BASTOS, 1984, p.21).

Observa-se, pelas narrativas desses moradores atingidos pela barragem que seus imaginários é povoado de miséria sobre a qual tiveram conhecimento pela televisão ou pela narrativa de amigos que vivem em outras cidades. As notícias que chegam às comunidades de Areia Branca e Rio do Salto sobre outras barragens, cujas indenizações atrasaram, contribuíram também para essa insegurança: "Fazer dívida com o Estado é um risco, demora ou então não paga a gente."

Dos oito moradores entrevistados, somente dois foram indenizados, os demais estão em fase de negociação com a Casan. Eles deram o seguinte depoimento.

\footnotetext{
Temos medo de não chegarmos a um acordo com a Casan e termos que sair daqui à força. A valoração da terra que nos foi dada é muito baixa. Alguns moradores daqui (de Areia Branca e Rio do Salto) entraram na Justiça para que as autoridades analisem o preço por hectare. Conseguimos pouca coisa com isso.
}

Percebe-se, nas falas dos moradores, a falta de consideração por parte dos órgãos responsáveis pelo projeto, pois faz dez anos que as propriedades foram valoradas, não sendo refeitas novas propostas.

Uma das entrevistadas mostra a indignação de ter que sair da comunidade cujos moradores não pediram para que fosse construída a 
barragem. Outros municípios é que serão beneficiados e não estão se importando com o problema que eles vêm enfrentando há anos. Em sua concepção, no seu local dá para viver muito bem, com dignidade. "Ter que migrar contra a vontade é muito ruim”, afirma. Tenho dó das pessoas mais antigas. Essas são as que estão sofrendo mais. Construíram sua vida neste local, criaram seus filhos, ajeitaram sua propriedade e sua casa como o gosto e agora são obrigadas a deixar tudo.

A migração é componente do processo de expropriação, desenraizamento e proletarização do camponês. Rompe assim seu mundo de relações pessoais para lançá-lo no mundo de relações contratuais. Assim sendo, os atingidos procuram recompor os laços de sociabilidades rompidas, se adaptar ao novo ambiente, se reorganizar socialmente (MARTINS, 1998, p. $31)$.

Constatam-se, nas falas dos moradores de Areia Branca, a tristeza ao verem as casas de moradores antigos serem levadas por caminhões e o desespero destes ao deixar seu local de origem, sua história, sua família.

\section{METODOLOGIA}

Esta pesquisa caracteriza-se por uma abordagem qualitativa, tendo como principal método a história de vida. Foi realizada nas comunidades de Areia Branca e Rio do Salto, no município de Timbé do Sul (SC).

O corpus da pesquisa é composto por oito moradores na faixa etária entre 40 e 80 anos.

Dos oito moradores entrevistados, cinco residem na comunidade de Areia Branca, e três em Rio do Salto. Houve um maior número de pessoas entrevistadas em Areia Branca em razão de a barragem ser construída toda nesse local, onde 250 pessoas serão desapropriadas de suas terras. Em Rio do Salto, o número de entrevistados foi menor, pois somente 50 pessoas serão desapropriadas de suas residências e, nessa área, serão feitos canais de distribuição de água. 
O estudo utilizou pesquisa bibliográfica e pesquisa de campo. Esta última foi efetivada em várias visitas às comunidades de Areia Branca e Rio do Salto durante os anos de 2009, 2010 e 2011. Nas visitas, foram feitas várias anotações sobre a dinâmica local das comunidades e registradas em um diário de campo, correspondendo a percepções da pesquisadora em relação às comunidades e seus moradores. O contato inicial com as pessoas entrevistadas foi realizado com a ajuda de um informante qualificado, conhecido por todos os membros da comunidade, durante o qual foi explicado o objetivo da pesquisa e cada morador teve direito a recusar ou participar das entrevistas.

A pesquisa de campo empregou a técnica de entrevista narrativa, na qual os moradores relataram livremente sua história de vida no local em que estão inseridos. Além da entrevista narrativa, também foram realizadas entrevistas semiestruturadas, nas quais foram colocadas questões aos moradores a fim de verificar na fala deles suas perspectivas quanto às mudanças que podem ocorrer em suas vidas referentes ao processo de desapropriação de suas terras.

Cada entrevista foi gravada e transcrita. Após as entrevistas, os moradores receberam uma máquina fotográfica, com a qual cada um fizeram fotos dos locais que mais se identificavam, ou seja, tinha maior apego. Ao término das entrevistas, foi deixado, pela pesquisadora, um caderno de brochura, a fim de averiguar a história de sua relação com a natureza e também para saber os locais onde já moraram. Cada entrevistado teve um prazo de um mês para fazer esta atividade, depois disso, a pesquisadora passou para recolher os cadernos e analisar os dados. Na referida pesquisa, com a devida permissão de cada entrevistado, usou-se seu nome original. Com o representante da CASAN foi realizada uma entrevista na modalidade estruturada.

A análise dos dados foi realizada por meio de conceitos chave retirados do referencial teórico e do repertório dos entrevistados. 


\section{PSICOLOGIA AMBIENTAL}

\section{Estudo da psicologia ambiental e interdisciplinaridade}

O estudo da inter-relação entre ambiente e indivíduo, geralmente, exige um trabalho interdisciplinar de especialistas de diversas áreas do conhecimento. Cada especialista pode captar, a partir de sua especialidade, aspectos significativos e trazer conhecimentos úteis para seu controle ou para a criação de programas alternativos.

Pela apropriação do espaço, o ser humano insere-se no processo de socialização a partir do momento em que se percebe sujeito em comunhão com a realidade que o circunda. Na relação homem-meio ambiente, analisa-se o comportamento deste e o meio em que vive. A identificação com essa realidade é o passo inicial e fundamental para que ocorra esse processo. Ao apropriar-se de um espaço ou de um lugar, a pessoa produz sua subjetividade e constrói sua identidade.

Uma das grandes contribuições da psicologia ambiental para os diversos profissionais que lidam com o espaço é a sensibilidade para o fato de que inúmeras variáveis, muitas vezes, não são tão aparentes à percepção, à análise e à interpretação do espaço e do ambiente. "A maneira como o homem lê o ambiente e como percebe o significado que o ambiente produz nele é que permitirá a transformação da pura percepção numa linguagem pessoal." (CARPIGIANI, 2007, p.42).

Günther et al (2004) afirmam que a psicologia ambiental nasceu com dupla vinculação ao estudo de problemas de degradação ambiental e elaboração de projetos para ambientes construídos. Essa subárea da psicologia evoluiu para abarcar muitos outros tipos de problemas no âmbito do fazer humano. O autor menciona os principais tipos de problemas que compõem na atualidade seu interesse.

[...] desde a percepção e a cognição do ambiente; efeito do ambiente no comportamento, ambientes diferenciados; ambientes específicos (como cidades); construção de determinados ambientes para obter determinados efeitos sobre 


o comportamento; mudanças de atitude, percepção e
comportamento frente ao ambiente; mudanças e
planejamentos do ambiente e preservação do meio ambiente
(Günther et al, 2004, p.25).

Proshansky, Ittelson e Rivlin (1970) apontam que a psicologia ambiental se diferencia das demais ciências devido à priorização de uma análise da interrelação ativa entre indivíduo e ambiente, não se limitando ao estudo de estímulos e respostas. Os autores abordam quatro aspectos que dão razão à existência dessa disciplina: estuda 0 ambiente ordenado e definido pelo indivíduo; seus problemas científicos estão relacionados com problemas sociais emergentes. "É de natureza multidisciplinar; estuda o indivíduo como parte integrada de toda a situação problemática" (GÜNTHER et al, 2005, p.3).

Ittelson (1973) afirma que o ser humano tem qualidades ambientais tanto quanto características psicológicas. Este pressuposto indica que as pessoas são componentes do ambiente, criando troca mútua entre elas, sendo instrumental para mensuração do comportamento humano em determinado meio físico. O autor citado fala que não há ambiente físico que não seja envolvido por um sistema social e, inseparavelmente, relacionado a ele.

A psicologia ambiental, nas palavras de Moser (1998), estuda a pessoa em seu contexto, tendo como tema central as inter-relações - e não somente as relações - entre a pessoa e o meio ambiente físico e social. As dimensões sociais e culturais estão sempre presentes na definição dos ambientes, mediando a percepção, a avaliação e as atitudes do indivíduo frente ao ambiente. Cada pessoa percebe, avalia e tem atitudes individuais em relação ao seu ambiente físico e social.

A psicologia ambiental troca diálogos interdisciplinares com a arquitetura, a geografia, a ecologia, as ciências sociais e com as diversas áreas da psicologia, como a social e a comunitária. Dessa forma, pode-se definir a atuação da psicologia ambiental como interdisciplinar e transdisciplinar ao fato de ser recente a criação desta como vinculada à psicologia, o que dificulta a especificação do que the seria um campo próprio e exclusivo de estudos (FREIRE, 2006, p.32). 
$\mathrm{Na}$ visão de Silveira (2009), por estar inserida em um campo interdisciplinar, a psicologia ambiental busca estabelecer vínculos com outras disciplinas interessadas na temática humano-ambiental e se preocupa em aplicar os conhecimentos advindos de pesquisas para melhorar a qualidade de vida de seus usuários, bem como a qualidade do ambiente.

Proshansky (apud Sánchez, 2005) ratifica a aspiração de interdisciplinaridade da seguinte forma:

\footnotetext{
Para muitos psicólogos ambientais, eu inclusive, o campo é, por definição, praticamente interdisciplinar, por ser concebido a partir de uma disciplina orientada para o problema $\mathrm{e}$ interessada em questões importantes da relação pessoa/ambiente no entorno urbano. De modo consciente ou não, ela se fundamenta em outros campos da psicologia, assim como em outras ciências do comportamento e das profissões do design (PROSHANSKY,1987, p.4).
}

Peluso (2003), salienta que a afeição entre a psicologia ambiental e a geografia se estabelece quando se entende o espaço e o ambiente como atores sociais. Esta autora ressalta que as relações indivíduo-ambiente podem ser compreendidas pelas representações sociais da casa própria. Um dos pressupostos apontados pela autora - que considera pequena a fronteira entre as duas ciências, pois ambas estudam as construções sociais, embora reconheça a especialidade de cada uma - é que é possível estabelecer um núcleo comum entre conhecimento, com a preocupação voltada para os problemas socialmente relevantes, e a busca de soluções coletivas para os mesmos.

\section{TERRITÓRIO, LUGAR E ESPAÇO}

Para Raffestin (1993, p.144), "o território se apoia no espaço, mas não é o espaço, é uma produção a partir do espaço. A produção de todas as relações que envolvem, se inscreve num campo de poder".

Lopes, por sua vez, afirma que o território é uma reordenação do espaço na qual a ordem está em busca dos sistemas informacionais dos quais 
dispõem o homem enquanto pertencente a uma cultura. "O território, segundo sua concepção, pode ser considerado como espaço informado pela biosfera" (LOPES et al, 2006, p.38).

Sack (apud LOPES et al, 2006) relata que a cultura, a tradição e a história mediam a mudança econômica, elas também mediam o modo como as pessoas e os lugares estão ligados, o modo como as pessoas usam a territorialidade e o modo como elas valorizam a terra. $O$ cotidiano das pessoas não envolve apenas um espaço esvaziável, "frio e abstrato", o próprio ato de consumir propõe criar contexto de afeto e significações. "Assim, a territorialidade, como um comportamento do poder, não é apenas um meio para criar e manter a ordem, mas é uma estratégia para criar e manter grande parte do contexto geográfico através do qual experimentamos o mundo e 0 dotamos de significado" (p. 38).

Além de território, é importante compreender o significado de espaço. Para Santos (2000), o espaço é um conjunto de objetos e um conjunto de ações. O autor afirma que o espaço que os seres humanos habitam é modificado todos os dias, através de tecnologias.

Nogueira (2009) relata que a constante produção e apropriação que o ser humano faz do espaço revela a importância deste elemento na constituição do humano: no espaço, homens e mulheres imprimem suas marcas, desenvolvem relações de poder e subsistência.

Santos (1994) define o espaço como coexistência do passado e do presente, reconstruída em um território sob um sistema técnico. O espaço é um conjunto de formas, contendo cada qual fração da sociedade em movimento.

Para Tuan, o espaço é mais abstrato do que lugar. "O que começa como espaço, indiferentemente, transforma-se em lugar à medida que reconhecemos melhor e adotamos valor a ele" (TUAN, 1983, p.6).

Santos (2000) comenta que toda a história não se escreve fora do espaço. No entanto, a história também não pode ser tomada por si só, pois precisa ser entendida de forma indissociável, por meio de sua espacialidade.

Um espaço em si, no entendimento de Gois, não se constitui um lugar até que seja afetivamente investido de significações. "Transformar espaços em 
lugares é identificar-se, é transformar estes espaços em algo que reflita a identidade de um grupo ou de uma comunidade" (GOIS, 2005, p.104).

Espaço e lugar, segundo Tuan, não podem ser definidos um sem 0 outro. "Espaço é algo que permite movimento, lugar é pausa; cada pausa no movimento torna possível que a localização se transforme em lugar" (TUAN, 1983, p.6).

Em geografia, o conceito de lugar está ligado aos espaços que nos são familiares, que fazem parte da nossa vida. "O nosso lugar nos dá identidade própria e nos permite estabelecer relações com lugares diferentes no resto do mundo" (ALMEIDA et al, 2007, p.8).

O lugar é o espaço de vivência de um grupo. É um ambiente conhecido praticamente por seus habitantes, que o utilizam em suas atividades cotidianas. "É um ambiente carregado de afetividade, pontilhado por artefatos sociais ou objetos naturais que servem como pontos de referência e, muitas vezes, evocam memórias pessoais. O lugar é uma parte essencial da identidade dos que o habitam" (MAGNOLI, 2005, p.24).

O lugar, segundo é o quadro de uma referência pragmática ao mundo, do qual the vêm solicitações e ordens precisas de ações condicionadas, mas é também o teatro insubstituível das paixões humanas, responsáveis, através da ação comunicativa, pelas mais diversas manifestações da espontaneidade e da criatividade. Em suas palavras, o lugar se define, pois, por sua densidade comunicacional e por densidade informacional cuja função os caracteriza e distingue (SANTOS, 2000, p.87).

Tuan vê o lugar como centro ao qual atribuímos valor e onde são satisfeitas as necessidades biológicas relacionadas à água, ao descanso, à alimentação e à procriação. "Os significados e as organizações atribuídas pelo homem ao espaço e ao lugar têm relação com fatores culturais, e estes próprios da espécie humana" (TUAN, 1983, p.95). O autor ainda ratifica que a passagem de lugar para espaço pode ocorrer por motivo de vergonha ou de dor. Dessa forma, certos espaços só se tornam lugares após uma demorada experiência. Para ele, lugar é segurança, é também lugar de liberdade que se sente quando se apega ao lugar. 


\section{Apropriação do espaço}

Para Gonçalves (2007), apropriação do espaço, na psicologia ambiental, envolve processos cognitivos, afetivos, interativos, simbólicos e estéticos. Os processos cognitivos referem-se a como o sujeito se localiza, se movimenta, onde vive. Nos processos simbólicos, destacam-se as diferentes formas com as quais a pessoa se identifica com o seu entorno, valoriza e preserva o lugar, e os processos afetivos estão relacionados à atração ao lugar e se este the proporciona bem-estar pessoal. A importância de todos esses componentes tem suas variações durante o ciclo de vida do ser humano. Assim, a pessoa passa a ser conhecedora do ambiente em que vive e habita, sentindo-se pertencente àquele lugar. $O$ processo de apropriação tem uma dinâmica em dois sentidos: um dirigido para a conquista do espaço; outro para si. Isso implica o sujeito adaptar o espaço às suas próprias necessidades, darIhe características próprias (GONÇALVES, 2007a, p.27).

A ocupação funcional num lugar é morar, porém, o sujeito só habita quando se apropria de todos os espaços que envolvem o físico, o simbólico, o emocional e o cultural. A apropriação como processo de identificação é, em certo sentido, um agente transformador, pois, ao apropriar-se do espaço, o sujeito deixa sua marca ao transformá-lo, iniciando assim um processo de reapropriação constante, que vai desde a casa aos objetos em seu interior. "Ao instalar-se numa casa vazia, o sujeito colocará nela objetos, utensílios, móveis. $\mathrm{Na}$ forma de organizar e decorar a casa, estão refletidos hábitos, valores e modos de vida de cada sujeito. O lugar se mostra carregado de emoções no enfeite da casa, no cuidado do jardim, na realidade por ele construída" (GONÇALVES, 2007, p.30).

Cada pessoa está rodeada por camadas concêntricas de espaço vivido, da sala para o lar, para a vizinhança, cidade, bairro e para a nação. O lar é onde a vida começa e termina; é o principal referencial de existência da espécie humana na medida em que este é a forma concreta do abrigo, da proteção contra as intempéries e outros perigos potenciais. O lar é o pivô de uma rotina diária. Vamos a todos os tipos de lugares (escola, trabalho, igreja, 
etc.), mas sempre retornamos ao lar, ou lugares semelhantes (abrigos, acampamentos, hotéis, etc.) (LEITE, 1998, p.12).

A subjetividade humana compreende um processo de construção social. "A subjetividade é o processo de invenção de si, a força da invenção da vida, de experimentação e apreensão particular e única do mundo através do modo como cada sujeito se produz como um indivíduo único, em transformação constante na experimentação cotidiana" (FURTADO, 2002 apud NOGUEIRA, 2009, p.71).

Tassara e Rabinovich (2001, p.217), referindo-se à subjetividade, abordam:

[...] a subjetividade expressar-se-ia pelas figuras que representam as imagens, por sua vez, alimentam os pensamentos que se opõem através de falas. O que se conhece do sujeito é aquilo que ele vai ser capaz de expressar a respeito de imagens que compõem o seu acervo experimental, mediado pela livre imagem, que não a define.

A respeito da subjetividade, Gonçalves afirma que, nos lugares do espaço, o sujeito desenvolve várias atividades, como morar, trabalhar, caminhar. Ele efetiva o processo de significação. É nesse lugar que cada sujeito produz a sua subjetividade. "De corpo inteiro e alma atenta, ele se apropria do espaço sentido, observado e visto" (GONÇALVES, 2007, p.126).

Gomes (2008) enfatiza que a apropriação pode, portanto, ser entendida como uma necessidade humana de enraizamento, que ocorre quando o eu se inscreve num lugar geográfico e, a partir daí, há o que se chama de criação de um ponto de referência, quando o espaço indefinido passa a ser importante para o sujeito que o vivencia.

A apropriação que o ser humano faz do espaço revela a importância desse elemento na constituição do humano: "no espaço homens e mulheres imprimem sua marca, desenvolvem relações de poder e de subsistência. $O$ espaço deve ser percebido pelos sujeitos que neles se movimentam, pela apropriação que dele é feita" (NOGUEIRA, 2009, p.70-73).

$\mathrm{Na}$ visão de Sansot (1996), o sujeito se apropria daquilo com o que se identifica. De acordo com Nogueira (2009), por meio da apropriação do espaço, os lugares são definidos. Nos espaços, os sujeitos sociais inscrevem suas marcas e desenvolvem suas histórias. 


\title{
IDENTIDADE
}

A identidade, no contexto desta discussão, é vista como um processo por meio de um processo, onde significações simbólicas relacionadas com práticas sociais vão produzir um ser coletivo.

Na perspectiva de (STREY, 1998), é do contexto histórico e social em que vive o homem que decorrem as possibilidades e impossibilidades, os modos e alternativas de sua identidade como formas histórico-sociais que constroem o processo de individuação. No entanto, a identidade se configura, ao mesmo tempo, como determinante, pois o indivíduo tem um papel ativo quer na construção desse contexto a partir de sua inserção, quer na sua apropriação. Sob essa perspectiva, é possível compreender a identidade pessoal e, ao mesmo tempo, identidade social, superando a falsa dicotomia entre essas duas distâncias.

Strey explica:

\author{
[...] os sistemas identificatórios são subdivididos, e a identidade \\ passa a ser qualificada como identidade pessoal (atributos \\ específicos do indivíduo) e/ou identidade social (atributos que \\ assinalam a pertença a grupos ou categorias); essa última \\ ainda recebe predicativos mais específicos como identidade \\ étnica, religiosa, profissional, etc. (STREY, 1998, p.161).
}

A psicologia ambiental, ao discutir a ligação que as pessoas estabelecem com lugares geográficos, fez uso do conceito de identidade, articulando-o às noções de lugar e apego (attachment), empreendendo estudos sobre identidade de lugar (place-identity) e de apego ao lugar (placeattachment). Essa linha de pensamento iniciou-se com Proshansky, Fabian e Kaminoff (1983), ao considerarem que, na teorização sobre identidade e conceito de self, inexiste uma discussão sobre o papel do ambiente físico. Propuseram, por esta razão, o conceito de identidade de lugar, "teoricamente concebido como aglomerados de cognições com valência positiva e negativa dos ambientes físicos" (GÜNTHER; ROZESTRATEN, 2005, p.2).

"Identidade de lugar, para Günther, Pinheiro e Lobo (2004), é, portanto, uma estrutura complexa constituída por atitudes, valores, crenças e 
significados referentes à relação psicológica que estabelecemos com os espaços físicos" (GÜNTHER; PINHEIRO e LOBO, 2004, p.3). O lugar foi incluído pelos autores como um subsistema da identidade do eu, cuja particularidade consiste na descrição e socialização da pessoa com o mundo físico.

A identidade do eu acolhida pela psicologia ambiental é reelaborada e reproduzida a cada relato que o sujeito faz de si e de seu entorno, remetendo-o a sua história de vida e à história do entorno ao qual pertence. Abre a possibilidade da escuta, através das narrativas da história de vida, da diversidade subjetiva responsável pela construção de um ambiente sóciohistórico, o que é desprezado nas definições das identidades totalizadoras comuns nas psicologias (ALENCAR; FREIRE, 2007).

A identificação com o ambiente, na psicologia ambiental, implica no sentimento de bem-estar e de familiaridade do sujeito com o seu entorno.

\footnotetext{
$\mathrm{Na}$ construção da identidade, existem dimensões e características do entorno físico que são incorporadas pelo sujeito por meio da interação com o ambiente. Nesse sentido, a identidade de lugar é um componente específico do próprio eu do sujeito, forjado em um complexo processo de ideias conscientes e inconscientes, sentimentos, valores e objetos (GONÇALVES, 2007, p.70).
}

As memórias passadas, experiências presentes e futuros sonhos de cada pessoa, nas palavras de Lopes e Bastos (2002), estão ligadas aos objetos que compreendem seu entorno.

Para a psicologia ambiental, o entorno faz parte do meio social concreto. O ambiente é a vivência concreta do sujeito. Nele, o sujeito trabalha, constrói sua casa, faz sua poética, constrói laços, apega-se, sente-se pertencente a um lugar, sonha, transforma. O conhecimento do entorno se faz pelos pés e pela cabeça; por nossos braços, nossas pernas (GONÇALVES, 2004, p.19).

O elo afetivo que há entre a pessoa e o lugar ou o ambiente físico é denominado topofilia. (MUNTANÕLA, 1996). "Esse sentimento de afetividade não é a emoção mais forte que o sujeito experimenta, mas, quando isso ocorre, é porque o meio ambiente ou o lugar conduz a emoções fortes ou é percebido 
como um símbolo pela pessoa" (MUNTANÕLA, 1996, p.43).

Tuan acredita que a topofilia pode ser despertada pela familiaridade. "Dessa forma, como somos capazes de nos afeiçoar aos nossos pertences pessoais, que podem ser entendidos como uma extensão da nossa personalidade, com o decorrer do tempo, o sujeito deposita parte de sua vida não somente no seu lar, mas também no seu bairro" (TUAN, 1983, p.148).

A noção de apego como adaptação é utilizada amplamente na psicologia ambiental por autores que não diferenciam a noção de apego a lugares com os de identidade de lugar e de apropriação do espaço. Essa perspectiva não responde à ética da alteridade. Contudo, há formas de conceber o apego a lugares, dentro da psicologia ambiental, numa perspectiva ética da alteridade (ALENCAR, 2007, p.322).

A psicologia ambiental, segundo Alencar (2007), contempla essa abertura do ambiente para o outro. A pessoa estabelece um vínculo afetivo estabelecido com o ambiente. "As pessoas unem-se a objetos de maneira peculiar. Assim como investem afeto nas relações de amizade, destinam a objetos afetos e valores que vão além daqueles traduzidos em valores pecuniários" (LOPES; BASTOS, 2002, p.78).

O apego ao lugar é um dos fatores fundamentais para o desenvolvimento da identidade da pessoa, ou seja, há lugares que têm um grande valor simbólico para o sujeito. A identificação com o local promove a capacidade de se vincular afetivamente a este, promovendo o apego ao lugar (LIMA; BOMFIM, 2009, p. 445).

\section{APROPRIAÇÃO DO ESPAÇO DOS MORADORES DE AREIA BRANCA E RIO DO SALTO}

Nas comunidades de Areia Branca e Rio do Salto, a constituição familiar tem características tradicionais. As famílias moram próximas umas das outras, o que, por um lado, favorece a colaboração mútua entre eles. Os oito entrevistados residem em ambas as comunidades há mais de 15 anos, dois 
são nativos e seis vieram de comunidades vizinhas. De uma forma ou outra, todos lutaram pelo desenvolvimento e o progresso não somente com recursos financeiros próprios, mas também com a ajuda de políticas públicas estaduais para a realização de melhorias na infraestrutura local.

Todos eles tiveram e ainda mantêm fortes laços com os elementos que compõem a natureza, brincadeiras na época de criança, quando brincavam nas horas de folga nos meios das matas, faziam balanços nas árvores, tomavam banhos nos rios, entre outros. Atualmente, essa integração se dá pelo lazer ou o trabalho, pois muitas das famílias sobrevivem da agricultura ou da extração de argila para as olarias.

Os moradores de Areia Branca e Rio do Salto, ao falar da natureza, compreendem que o ar, a vegetação, os animais e a água são elementos fundamentais recebidos diariamente, e são gratos à natureza por isso.

O grande bem precioso dos moradores é a água que utilizam em suas casas, direto da nascente, pura e cristalina. Poderão migrar para qualquer lugar e não encontrarão água da mesma forma.

A cultura é o grande unificador das relações dos moradores de Areia Branca e Rio do Salto, sendo comuns tradições como novenas realizadas no período de Quaresma e Natal, entre outras datas. Essas, porém, são comemoradas entre grupos de famílias. No período da Quaresma, na SextaFeira Santa, fazem as chamadas procissões, em que é escolhido um percurso até a igreja, sendo colocadas várias cruzes à beira da estrada como sinal de divindade. As festas realizadas nas comunidades têm características tradicionais, havendo maior movimento nas ruas devido ao fato de os moradores se prepararem para o grande dia com a compra de roupas novas e também com o recolhimento de prendas para ofertarem nas novenas que antecedem a festa.

O enraizamento de sentimentos, a assimilação e a consequente incorporação da cultura local, segundo Foetsch (2005), contribuem para a formação da identidade de lugar; e, esse sentido de identidade envolve percepção, se apresenta carregado de satisfação, reminiscência e felicidade, como um somatório das dimensões simbólicas ao encarar as experiências 
banais e aspirações humanas. Nesse contexto, acredita-se que as ideias a respeito do espaço brotam dos seres humanos, não somente com relação aos laços de afetividade que os unem ao lugar, mas também desde os aspectos mais banais do dia a dia, e, por ser uma referência de valores e sentimentos, o lugar lembra as experiências e aspirações dos seres humanos, sendo assim fundamental para sua identidade.

O espaço constitutivo pelas famílias nas comunidades residentes é permeado de amor. Os momentos de proximidade entre eles são preciosos no estabelecimento de uma rede solidária, fraterna, da qual resulta o compartilhar não apenas da casa, mas das histórias de vida, experiências, brincadeiras. Conforme Tuan (1983), o lugar é um centro de significados construídos pelas experiências. No lugar desenvolvem-se referências afetivas ao longo da vida a partir da convivência com o lugar e o outro.

Os oito moradores entrevistados participam da vida social de ambas as comunidades, e os lugares mais frequentados por eles são a igreja, os bares, a casa dos vizinhos, entre outros.

Os lugares que os entrevistados das comunidades de Areia Branca e Rio do Salto escolheram como de maior apego, ou seja, com os quais mais se identificam são cômodos da casa, como cozinha, quarto, sala e varanda. Uma das moradoras, além de se identificar com a cozinha em razão de passar ali boa parte de seu tempo, também tem um bom compartilhamento com o local de trabalho, nesse caso a fábrica de cerâmica olaria), um dos lugares integrantes de troca de informações e de onde tira sua renda.

Uma das entrevistadas se identificou com o entorno da casa, nesse caso o pomar. Segundo a entrevistada, o pomar é o lugar que the transmite muita paz, harmonia e prazer. Ao chegar a esse ambiente, fica maravilhada com o canto dos pássaros, o cheiro das flores. Todos os moradores foram unânimes em dizer que, quando uma pessoa se identifica com um lugar em específico, procura ficar a maior parte do tempo nele. "Quando criamos uma identidade com o lugar em que vivemos; ele é algo para nós, nossa memória guarda sobre ele percepções e vivências com as quais nos identificamos. "Portanto, estabelecemos com o lugar uma relação de afetividade" (TERRA, 2005, p.5). 
Dos oito moradores entrevistados das comunidades de Areia Branca e Rio do Salto, sete se apropriaram de todos os espaços desde a casa ao entorno físico e social. Uma das moradoras ainda não conseguiu se adaptar ao local em que está inserida atualmente. Em sua visão, o lugar que habita fica próximo de um morro, há muita sombra, no inverno é muito frio, demora para aparecer o sol, as estradas são mal cuidadas e o acesso ao centro da cidade é longe. Mesmo morando muito tempo em Rio do Salto, não se sente pertencente ao lugar, concretizando a afirmação de Leite (1998), segundo a qual uma pessoa pode ter vivido durante toda sua vida em um determinado local e sua relação com ele ser completamente irreal, sem nenhum enraizamento.

Referindo-se, particularmente, à mudança de ambiente devido à construção da barragem, os entrevistados demonstraram grande apreensão, pois suas histórias de vida e seus sonhos ficarão debaixo d'água. Terão que se readaptar a um novo meio, cuja formação não teve nenhuma contribuição sua. Além de tudo, haverá mudança de habitat, de vizinhos, de parentescos e a água que tanto estimam não será a mesma. Uma das entrevistadas dá o seguinte relato:

\footnotetext{
Não sei como os vizinhos são. A casa não será a mesma. $O$ lugar não será o mesmo. Não sei se a vizinhança é boa, se podemos confiar neles. Aqui onde eu moro, a gente se apega aos animais, no quintal, tudo é muito bom. Se quiser uma fruta, tem por todo lado, na beira das estradas, se não tem, os vizinhos dão.
}

O abandono da comunidade, além da dificuldade de adaptação a outros lares, faz com que muitas pessoas sintam medo da remoção de seus domicílios, insegurança de não conseguirem imóveis similares aos seus e também de não manterem o mesmo padrão de vida. Dessa forma, segundo Santos (2006), quando o homem se defronta com o espaço que não ajudou a criar, cuja história desconhece e a memória lhe é estranha, esse lugar é a sede de uma alienação. Não existindo, portanto, nesse novo espaço a ser ocupado o sentimento de pertença que ficou sob as águas.

Santos (2006), afirma que, ao ir para um novo local, certamente, a pessoa 
deixa para trás uma cultura herdada, para se defrontar com outra. Sua relação com o novo morador se manifesta dialeticamente como territorialidade nova e cultura nova, que interferem reciprocamente, mudando-se paralelamente territorialidade e cultura e mudando o homem.

\section{CONSIDERAÇÕES FINAIS}

Através dos aspectos da apropriação do espaço, verificou-se por parte de todos os moradores entrevistados das comunidades de Areia Branca e Rio do Salto um grande sentimento de pertença ao lugar. A apropriação dos espaços pelos entrevistados se dá pela singularidade dos sujeitos e pela coletividade, pois deixam marcas no espaço por meio do afeto, do simbolismo e da cultura que ainda possuem fortes elementos de solidariedade e de espírito de vizinhança. Dos oito moradores entrevistados, sete escolheram como lugar de grande apego cômodos da casa, como cozinha, quarto, sala e varanda. Uma das entrevistadas se identificou com o entorno da casa, ou seja, o pomar. Houve também por parte de uma das entrevistadas um compartilhamento com o local de trabalho, nesse caso, a cerâmica.

Nos aspectos cognitivos, verificou-se uma ampla capacidade dos moradores em orientar-se no espaço físico, enfatizando a água, o solo, a vegetação e os animais, isto é, todos, de uma forma ou de outra, relacionaramse com esses aspectos, seja por meio do trabalho ou do lazer.

Nos aspectos simbólicos, encontrou-se uma linguagem muito rica que envolve todos os espaços físicos, sociais, psíquicos e culturais. Por serem parte de uma comunidade tradicional, a cultura é o grande unificador dessa população. O simbolismo está diretamente relacionado às crenças, aos valores, às tradições que procuram manter vivas, apesar de suas transformações.

Alguns moradores davam maior atenção aos cuidados da casa, do jardim, do pomar, mantendo sempre bem organizados e limpos. Outros se preocupavam com o cuidado da comunidade e da área de trabalho, neste caso 
a roça, o que denota um forte sentimento de pertencimento ao lugar, pois o conceito de cultivação da psicologia ambiental aí se faz presente.

No vínculo afetivo, evidenciou-se um forte sentimento de pertencer à comunidade. O amor é significativo no cuidado com a cultura. O relacional dessas comunidades demonstrou fortes vínculos com a vizinhança e, principalmente, com a água.

\section{REFERÊNCIAS BIBLIOGRÁFICAS}

ALENCAR, Helenira Fonseca de; FREIRE, José Célio. O lugar da alteridade na psicologia ambiental. Rev. Mal-Estar. Subj. Fortaleza, v.7, n.2, 2007.

ALENCAR, Helerina Fonseca. O lugar da alteridade na psicologia ambiental. 2007. TCC (Graduação em Psicologia Ambiental) - Universidade do Ceará (UFC), Ceará.

BASTOS, Elide Rugai. As ligas camponesas. Petrópolis: Vozes, 1984.

EPAGRI - Empresa de Pesquisa Agropecuária e Extensão Rural de Santa Catarina S.A. Barragem Rio do Salto: Estudo de Impacto Ambiental - EIA e Relatório de Impacto Ambiental - RIMA. Criciúma: EPAGRI, 2006.

EPAGRI - Empresa de Pesquisa Agropecuária e Extensão Rural de Santa Catarina S. A. Barragem do Rio do Salto: Relatório de Impacto Ambiental (RIMA). Criciúma: EPAGRI, 2000.

ESTEVES, Egeu Gómez. Sócio Trabalhador: Uma Identidade Psicossocial em construção! Princípios da Economia Solidária. In: ENCONTRO INTERNACIONAL DE ECONOMIA SOLIDÁRIA, 5, 2010, São Paulo: USP, 2010, 1-9.

GÓIS, Cezar Wagner. Atividade e Consciência. Fortaleza: Instituto Paulo Freire, 2005.

GOMES, Carla Cristina de Araújo. O apego pelo lugar de morar. 2008. Dissertação (Mestrado em Desenvolvimento e Planejamento Territorial) Universidade Católica de Goiás, Goiânia.

GONÇALVES, Teresinha Maria. Cidade e poética: um estudo de psicologia ambiental sobre o ambiente urbano. ljuí: Unijuí, 2007.

GONÇALVES, Teresinha Maria. Psicologia Ambiental. Revista Pesquisa e Extensão em Saúde, Criciúma, v. 1, n. 1, p. 17-21, 2004. 
GONÇALVES, Teresinha Maria; MARTINEZ, Joyde Giacomini. Educação Ambiental Crítica: Pensando o Ambiente Urbano. In: GONÇALVES, Teresinha Maria; SANTOS, Robson dos. Cidade e meio ambiente: estudos interdisciplinares. Criciúma: UNESC, 2010.

GÜNTHER, Harmut; ROZESTRATEN, Reinier J. A. Psicologia Ambiental: Algumas Considerações sobre sua Área de Pesquisa e Ensino. Laboratório de Psicologia Ambiental, Brasília, n.10, p.1-7, 2005.

GÜNTHER, Hartmut; PINHEIRO José Q.; LOBO, Raquel Souza. Psicologia ambiental: entendendo as relações do homem com seu ambiente. Campinas: Alínea, 2004.

JORNAL SEM CENSURA. Barragem Rio do Salto é Tema de Discussão na Secretaria de Desenvolvimento Regional. Araranguá: Jornal sem Censura, nov. 2010. Disponível em: http://www.jornalsemcensura.com.br. Acesso em: 20 nov. 2011.

KAIMOTI, Naiara Luchini de Assis. Paisagens Vivenciadas. Apropriações Públicas dos Fundos de Vale e Sistemas de Espaços Livres. Estudo de Caso no Município de Bauru-SP. São Paulo: FAU/PROCAM, 2009.

LEFF, Enrique-Saber. Epistemologia Ambiental. 2. ed. São Paulo: Cortez, 2002.

LEITE, Adriana Filgueira. O Lugar: Duas Acepções Geográficas. Anuário do Instituto de Geociências, Rio de Janeiro, v.21, 1998.

LIMA, Deyseane Maria Araújo; BOMFIM, Zulmira Áurea Cruz. Vinculação afetiva pessoa-ambiente: Diálogos na psicologia comunitária e psicologia ambiental. Psico/UFRGS, Porto Alegre, v. 40, n. 4, p.491-497, outldez 2009.

LOPES, Luiz Paulo da Moita; BASTOS, Liliane Cabral. Identidade: recordes multi e interdisciplinares. Campinas: Mercado De letras, 2002.

MARTINS, José Souza. O cativeiro da terra. 7 ed. São Paulo: Hucitec, 1998. MUNTANỐLA, Thornberg Josep. La arquitetura como lugar. Barcelona: EUPC, 1996.

NOGUEIRA, Maria Luisa Magalhães. Subjetividade e materialidade: Cidade, Espaço e Trabalho. Fractal: Revista de Psicologia, v.21, n.1, p.69-86, jan./abr. 2009.

PELUSO, M. L. O potencial das representações sociais para a compreensão interdisciplinar da realidade: Geografia e Psicologia Ambiental. Estud. Psicol (Natal), Natal, v. 8 n. 2, 2003. Disponível em: http://www.scielo.br.php-scrip-sci. Acesso em: 12 set 2009. 
POL, Enric. La apropiación Del espácio. In: IÑIGUEZ, Lupicinio; POL, Enric. (Orgs.). Cognicion, representacion y apropriación Del espacio. Barcelona: Universitat de Barcelona Publicacions, 1996.

PROSHANSKY, Harold; FABIAN, Abbe; KAMINOFF, Robert. Appropiation et nonappropiation (misappropiation) de l'espace. [s.l.:s.n.], 1976.

REIS, Maria José. O movimento dos Atingidos por Barragens: ATORES, estratégias de luta e conquista. In: SEMINÁRIO NACIONAL DE MOVIMENTOS SOCIAIS. PARTICIPAÇÃO E DEMOCRACIA, 2, 2007, Florianópolis: UFSC, 25-27 de abr. 2007, p.473-501.

SANCHEZ, Euclides. A Psicologia Ambiental e sua Possibilidades de interdisciplinaridade. Psicologia USP, São Paulo, v. 16, n. 3, p.195-206, 2005.

SANSOT, Pierre. Poética de La Ville. Paris: Armand Colin, 1996.

SANTOS, Milton. Território, territórios: ensaio sobre o ordenamento territorial. 2 ed. Rio de Janeiro: DP\&A, 2006,

SÈVE, Lucien. A personalidade em gestão. In: SILVEIRA, Paulo; DORAY, Bernard. (Orgs). Elementos para uma teoria marxista da subjetividade. São Paulo: Vértice, 1989, p.147-178.

STREY, Marlene Neves. Psicologia Social Contemporânea: Livro-textoMarlene Neves Strey. Petrópolis: Vozes, 1998.

TASSARA, Eda T. O; RABINOVICH, E. P. A invenção do urbano e o poético: uma cartografia afetiva - Estudo sobre o bairro paulista da Barra Funda. In: PINHEIRO, José Q. (Org). Panoramas Interdisciplinares para uma psicologia ambiental do urbano. São Paulo: Educ; Fapesp, 2001.

TERRA Lygia. Geografia geral e geografia do Brasil: o espaço natural socioeconômico. São Paulo: Moderna, 2005.

TUAN,Yi-Fu. Espaço e lugar: a perspectiva da experiência. São Paulo: Difel, 1983.

Recebido em 15/12/2011.

Aceito em 20/03/2012. 